\title{
Intracranial Multiple Myeloma After Chemotherapy
}

\section{Michael Kogan MD PhD ${ }^{1,3}$ and Adnan H. Siddiqui MD PhD ${ }^{1-5^{*}}$}

${ }^{1}$ Department of Neurosurgery, Jacobs School of Medicine and Biomedical Sciences, University at Buffalo, State University of New York, Buffalo, New York, USA

${ }^{2}$ Department of Radiology, Jacobs School of Medicine and Biomedical Sciences, University at Buffalo, State University of New York, Buffalo, New York, USA

${ }^{3}$ Department of Neurosurgery, Gates Vascular Institute at Kaleida Health, Buffalo, New York, USA

${ }^{4}$ Toshiba Stroke and Vascular Research Center, University at Buffalo, State University of New York, Buffalo, New York, USA

5 Jacobs Institute, Buffalo, New York, USA

"Corresponding Author: Adnan H. Siddiqui MD, University at Buffalo Neurosurgery, 100 High Street, Suite B4

Buffalo, NY 14203 USA, Tel: 716218 1000; Fax: 716859 7479; Email: editorial@ubns.com

Received: 08 August 2017; Accepted: 15 August 2017; Published: 18 August 2017

\section{Introduction}

Intracranial localization is reported in $<1 \%$ of cases of multiple myeloma [1], with pachymeningeal and leptomeningeal lesions associated with hematogenous spread [2]. Interestingly, the incidence of central nervous system (CNS) myeloma has been increasing, which may be reflective of new chemotherapeutic agents used to treat the primary manifestation [3].

2. Keywords: Central nervous system; Chemotherapy; Intracranial; Multiple myeloma; Bortezomib; Leptomeningeal; Pachymeningeal; Stem-cell transplant

\section{Case Report}

A 68-year-old African-American woman with a history of multiple myeloma in remission presented with slurred speech. Computed tomography of the head showed multiple hemorrhagic lesions (Figure 1A and 1B). Brain magnetic resonance imaging confirmed pachymeningeal involvement (Figure 1C and 1D). A diagnosis of monoclonal gammopathy had been made 7 years prior to the present admission. She developed multiple myeloma $1 \frac{1}{2}$ years prior. She was beta-2-macroglobulin positive and underwent induction chemotherapy with lenalidomide, 
bortezomib, and dexamethasone. A bone marrow biopsy performed 4 months prior to the present admission was negative. Bortezomib therapy alone was maintained. No stem-cell transplant was performed.
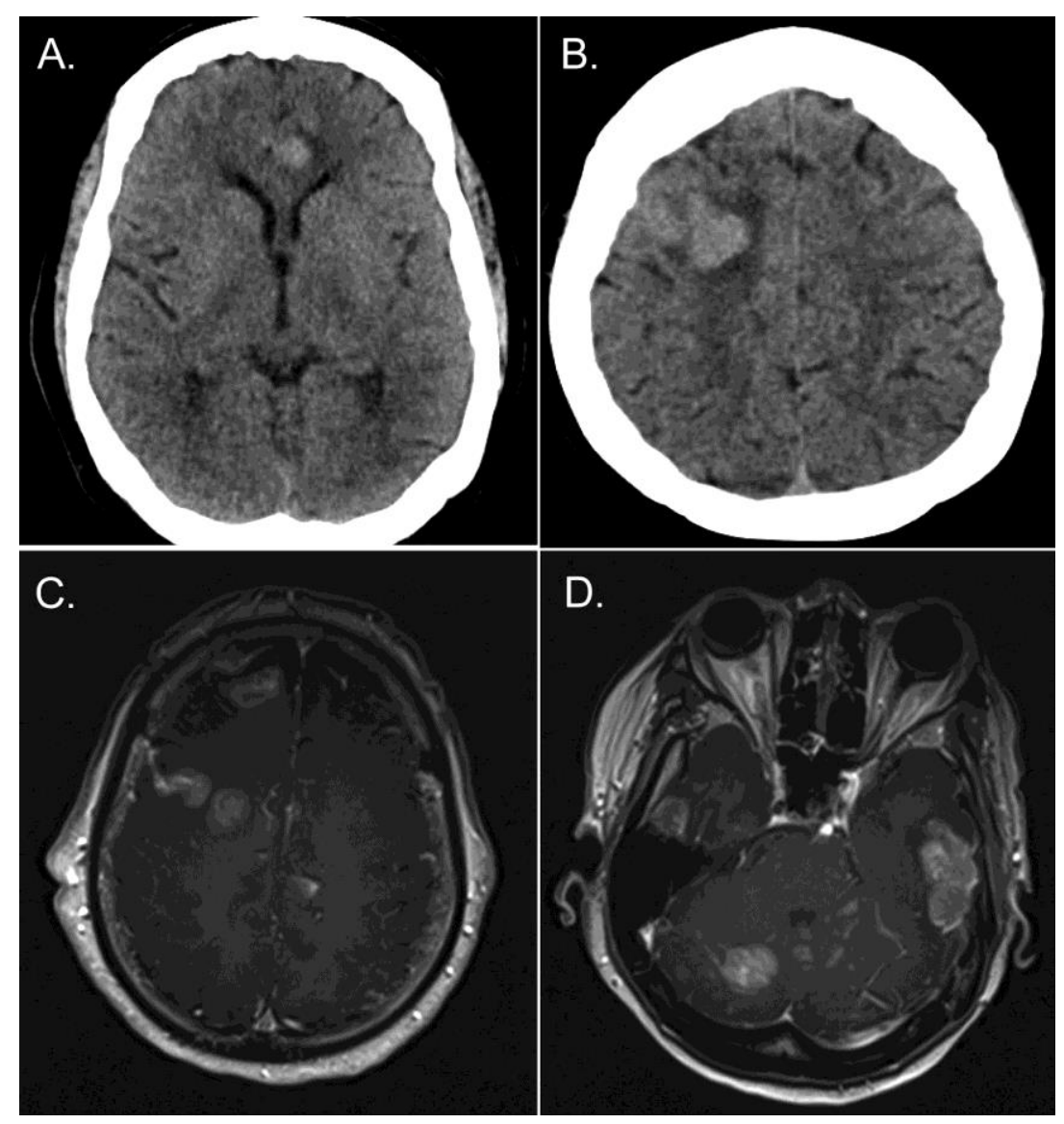

Figure 1: Computed tomographic scans obtained at the time of admission, with evidence of hemorrhagic tumor growth (A-B). Admission magnetic resonance T1-weighted images with contrast enhancement showing multiple pachymeningeal lesions (C-D).

Our workup revealed no lesions other than a questionable T2 spinal process lesion. We performed a right-sided excisional biopsy of a superficial temporal lesion to establish the diagnosis, which confirmed the presence of plasmacytoid cells.

\section{Discussion}

In a recent review, 7 patients who underwent stem cell transplant and treatment with novel agents for multiple myeloma developed intracranial disease [3]. Our case is an unusual presentation of isolated intracranial disease in conjunction with complete remission on sole bortezomib therapy (subsequent to induction combination chemotherapy) and no stem-cell transplant.

\section{Conclusion}

This case highlights the possibility that CNS manifestation may be related to potential lack of blood-brain barrier penetrance of novel agents [1]. 


\section{Author Contributions}

Conception and design: both authors. Acquisition of data: both authors. Analysis and interpretation of data: both authors. Drafting the manuscript: Kogan. Critically revising the article: both authors. Reviewed submitted version of manuscript: both authors.

\section{Financial Relationships/Potential Conflicts of Interest (none directly related to this work)}

Kogan: None. Siddiqui: Financial interests:Buffalo Technology Partners Inc., Cardinal, International Medical Distribution Partners; Medina Medical Systems, Neuro technology Investors, StimSox, Valor Medical; Consultant:Amnis Therapeutics Ltd., Cerebrotech Medical Systems Inc., CereVasc LLC, Codman, Corindus Inc., Covidien (acquired by Medtronic), GuidePoint Global Consulting, Lazarus (acquired by Medtronic), Medina Medical (acquired by Medtronic), Medtronic, MicroVention, Neuravi, Penumbra, Pulsar Vascular, Rapid Medical, Rebound Medical, Reverse Medical (acquired by Medtronic), Silk Road Medical Inc., Stryker, The Stroke Project Inc., Three Rivers Medical Inc., W.L. Gore \& Associates; Principal Investigator/National Steering Committee:Covidien SWIFT PRIME Trial, LARGE Trial, Medtronic SWIFT DIRECT, MicroVention CONFIDENCE Study, MicroVention FRED Trial, Penumbra 3D Separator Trial, Penumbra COMPASS Trial, Penumbra INVEST Trial, POSITIVE Trial; Board Member:Intersocietal Accreditation Committee.

\section{References}

1. Fassas AB, Muwalla F, Berryman T, et al. Myeloma of the central nervous system: association with highrisk chromosomal abnormalities, plasmablastic morphology and extramedullary manifestations. $\mathrm{Br} \mathrm{J}$ Haematol 117 (2002): 103-108.

2. Moulopoulos LA, Granfield CA, Dimopoulos MA, et al. Extraosseous multiple myeloma: imaging features. AJR Am J Roentgenol 161 (1993): 1083-1087.

3. Gangatharan SA, Carney DA, Prince HM, et al. Emergence of central nervous system myeloma in the era of novel agents. Hematol Oncol 30 (2012): 170-174.

This article is an open access article distributed under the terms and conditions of the Creative Commons Attribution (CC-BY) license 4.0 